\title{
Exposure to cigarette smoke impacts myeloid-derived regulatory cell function and exacerbates airway hyper-responsiveness
}

\author{
Yong Wang ${ }^{1}$, Tong Huan Jin ${ }^{1}$, Aisha Farhana ${ }^{2}$, Jason Freeman² ${ }^{2}$ Kim Estell ${ }^{3}$, Jaroslaw W Zmijewski ${ }^{1}$, Amit Gaggar ${ }^{1}$, \\ Victor J Thannickal ${ }^{1}$, Lisa M Schwiebert ${ }^{3}$, Adrie JC Steyn ${ }^{2,4}$ and Jessy S Deshane ${ }^{1}$
}

Cigarette smoking enhances oxidative stress and airway inflammation in asthma, the mechanisms of which are largely unknown. Myeloid-derived regulatory cells (MDRC) are free radical producing immature myeloid cells with immunoregulatory properties that have recently been demonstrated as critical regulators of allergic airway inflammation. NO (nitric oxide)-producing immunosuppressive MDRC suppress T-cell proliferation and airway-hyper responsiveness (AHR), while the $\mathrm{O}_{2}{ }^{--}$(superoxide)-producing MDRC are proinflammatory. We hypothesized that cigarette smoke (CS) exposure may impact MDRC function and contribute to exacerbations in asthma. Exposure of bone marrow (BM)-derived NO-producing MDRC to CS reduced the production of NO and its metabolites and inhibited their potential to suppress T-cell proliferation. Production of immunoregulatory cytokine IL-10 was significantly inhibited, while proinflammatory cytokines IL-6, IL-1 $\beta$, TNF- $\alpha$ and IL-33 were enhanced in CS-exposed BM-MDRC. Additionally, CS exposure increased NF- $\kappa$ B activation and induced BM-MDRC-mediated production of $\mathrm{O}_{2}{ }^{\bullet-}$, via NF- $\kappa \mathrm{B}$-dependent pathway. Intratracheal transfer of smoke-exposed MDRC-producing proinflammatory cytokines increased NF- $\kappa$ B activation, reactive oxygen species and mucin production in vivo and exacerbated AHR in C57BL/6 mice, mice deficient in Type I IFNR and MyD88, both with reduced numbers of endogenous MDRC. Thus CS exposure modulates MDRC function and contributes to asthma exacerbation and identifies MDRC as potential targets for asthma therapy.

Laboratory Investigation (2014) 94, 1312-1325; doi:10.1038/labinvest.2014.126; published online 3 November 2014

Allergen-stimulated dysregulation of immune responses causes airway inflammation in asthmatics. ${ }^{1,2}$ Infiltrating innate immune cells have been implicated as primary contributors of oxidative stress during asthma, while $\mathrm{CD} 4^{+}$ $\mathrm{T}$ helper cells drive the persistence and resolution of the inflammatory response. ${ }^{3-9}$ Free radical species are important mediators of allergic airway inflammation. ${ }^{10-12}$ Cigarette smoking enhances the severity of asthma by exacerbating inflammation, oxidative stress and tissue injury in the respiratory tract. ${ }^{13-16}$ Cigarette smoke (CS) also has the potential to modulate free radical concentrations in the human airways and regulate the recruitment of inflammatory immune cells. ${ }^{17-21}$ In murine models of asthma, exposure to CS has an adjuvant effect on eosinophils and Th2 cytokines $^{13,14}$ and has recently been shown to induce production of IL-1 family proinflammatory cytokine IL-33, which promotes airway inflammation..$^{22-28} \mathrm{CS}$ exposure also causes activation and recruitment of alveolar macrophages ${ }^{17-19}$ and/or other inflammatory cells and causes production of reactive oxygen species (ROS), all of which contribute to lung inflammation. ${ }^{10,12,21}$ In humans, exposure to environmental smoke and CS reduces exhaled NO, suggesting a direct effect of CS on NO production in the human airways. ${ }^{20,21,29,30}$

We and the others have reported that two distinct subsets of immature myeloid cells that generate NO (nitric oxide) and superoxide $\left(\mathrm{O}_{2}{ }^{\bullet-}\right)$ termed myeloid-derived regulatory cells (MDRC) are important regulators of allergic airway inflammation. ${ }^{31,32}$ NO-producing MDRC suppress, while $\mathrm{O}_{2}{ }^{\bullet-}$-producing MDRC are proinflammatory in both in vitro T-cell responses and in vivo airway hyper-responsiveness

\footnotetext{
Department of Medicine, The University of Alabama at Birmingham, Birmingham, AL, USA; ${ }^{2}$ Department of Microbiology, The University of Alabama at Birmingham, Birmingham, AL, USA; ${ }^{3}$ Department of Cell Developmental and Integrative Biology, The University of Alabama at Birmingham, Birmingham, AL, USA and ${ }^{4} \mathrm{KwaZulu}-$ Natal Research Institute for Tuberculosis and HIV, Durban, South Africa

Correspondence: Dr JS Deshane, PhD, Department of Medicine, Division of Pulmonary, Allergy and Critical Care Medicine, University of Alabama at Birmingham, 1900 University Boulevard, THT-433, Birmingham, AL 35294, USA.
}

E-mail: treena@uab.edu

Received 10 July 2014; revised 8 September 2014; accepted 12 September 2014 
(AHR) in murine models of asthma. We investigated here whether CS exposure modulated the immunosuppressive potential of MDRC by switching the free radical profile of MDRC. Herein, we report that exposure to CS exposure inhibits MDRC-mediated suppression of T-cell proliferation by reducing their production of $\mathrm{NO}$, immunoregulatory cytokines TGF- $\beta$ and IL-10, while enhancing the production of proinflammatory cytokines, importantly IL-33. Furthermore, exposure to CS switches the phenotype of MDRC to ROS-producing cells via an NF- $\kappa \mathrm{B}$-dependent mechanism. Importantly, intratracheal adoptive transfer of smokeexposed MDRC exacerbated ovalbumin-induced murine asthma.

\section{MATERIALS AND METHODS \\ Mice}

C57BL/6 were obtained from The Jackson Laboratory (Bar Harbor, ME). OT-II mice were provided by Paul Allen (Washington University, St Louis, MO). The original MyD88-deficient mice were obtained under a Materials Transfer Agreement from Dr Shizuo Akira (Osaka University, Japan) and were generously provided to us by Suzanne M Michalek (University of Alabama, Birmingham, $\mathrm{AL})$. The IFNAR-deficient mice were derived by John Mountz in C57BL/6 background and were provided by Chander Raman (both from the University of Alabama, Birmingham, AL). Mice 6-8 weeks of age were housed under pathogen-free conditions in micro-isolator cages, and experiments were approved by the institutional animal care and use committee of the University of Alabama at Birmingham.

\section{In vitro Differentiation of Bone Marrow (BM) MDRC}

BM cells were flushed from femurs using PBS and were cultured in RPMI medium supplemented with $10 \%$ heatinactivated fetal bovine serum, $100 \mathrm{U} / \mathrm{ml}$ of penicillin and $100 \mu \mathrm{g} / \mathrm{ml}$ of streptomycin sulfate, $1 \mathrm{mM}$ sodium pyruvate (all cell culture reagents were obtained from Life Technologies, Grand Island, NY) and $50 \mu \mathrm{M}$ 2-mercaptoethanol (Sigma, St Louis, MI) and containing $20 \mathrm{ng} / \mathrm{ml}$ granulocytemacrophage colony-stimulating factor (GM-CSF, R\&D Systems, Minneapolis, MN) and $1 \mu \mathrm{g} / \mathrm{ml}$ Lipopolysaccharide (LPS from Escherichia coli, strain O26:B6, Sigma, MI) as described before. ${ }^{31}$ BM cells were cultured for 5 days and non-adherent cells were collected and restimulated for additional 3 days at $37^{\circ} \mathrm{C}$.

\section{Flow Cytometry}

The in vitro differentiated BM-MDRC were prepared for flow cytometry by first incubating in FACS staining buffer (PBS $+3 \%$ FBS) containing $2.0 \mu \mathrm{g} / \mathrm{ml}$ of the mAb $2.4 \mathrm{G} 2$ (BD Pharmingen, Franklin Lakes, NJ) at $4{ }^{\circ} \mathrm{C}$ for $30 \mathrm{~min}$. These cells were then stained with several fluorochrome-conjugated anti-mouse monoclonal antibodies for cellular phenotyping as follows: PE-labeled anti-mouse Gr-1 (clone: RB6-8C5),
PerCPcy5.5-labeled anti-mouse Ly-6C (clone: HK1.4), FITClabeled anti-mouse Ly-6G (clone: 1A8), APC-labeled antimouse F4/80 (clone: BM8), PE-labeled anti-mouse PDL-1 (clone: M1H5), PECy-7-labeled anti-mouse CD11c (clone: N418), PE-labeled anti-mouse CD115 (clone: AFS98) (all these antibodies were obtained from eBiosciences, San Diego CA); APCCy-7 labeled anti-mouse CD11b (clone: M1/70) and PE-labeled anti-mouse CD124 (clone: mIL4-RM1) from BD Biosciences, San Jose, CA; and PE-labeled antimouse iNOS (Santa Cruz Biotechnologies, Dallas, TX).

\section{CS Exposure of BM-MDRC}

BM-MDRC were exposed to smoke generated from one 3R4F Kentucky Reference Cigarette (University of Kentucky). CS exposure was performed using a TE-10 smoking machine connected to an exposure chamber (Teague Enterprises). Each smoldering cigarette was puffed for $2 \mathrm{~s}$ once every minute for a total of 8 puffs at a flow rate of $1.051 / \mathrm{min}$ to provide a standard puff of $35 \mathrm{~cm}^{3}$. The total suspended particulate level was $28.1 \pm 0.5 \mathrm{mg} / \mathrm{m}^{3}$ estimated from two separate exposures. MDRC were washed twice in PBS after smoke exposure, and viability was determined by trypan blue exclusion and cultured for additional $24 \mathrm{~h}$ in RPMI media as described above. Culture supernatants were harvested for cytokine analyses, and cell lysates were prepared for western blotting analyses as described below.

\section{T-Cell Proliferation}

Naive $\mathrm{CD} 4{ }^{+} \mathrm{CD} 25^{-} \mathrm{CD} 62 \mathrm{~L}^{\text {hi }} \mathrm{CD} 44^{\text {lo }}$ OVA-specific $\mathrm{CD} 4^{+}$ $\mathrm{T}$ cells were sorted from the spleens of OT-II mice and were labeled with CFSE as described before. ${ }^{32}$ Co-cultures were carried out using $10^{5} \mathrm{~T}$ cells and $10^{5}$ smoke-exposed or unexposed MDRC and $10^{4}$ BMDC pulsed with OVA peptide. T-cell proliferation was measured as dilution of CFSE using flow cytometry after $72 \mathrm{~h}$ of co-culture.

\section{Western Blotting Analyses}

Total homogenates were prepared from smoke-exposed or control BM-MDRC or lung tissue of adoptive transfer recipient mice following i.t. transfer of smoke-exposed or control BM-MDRC. Tissues were harvested following perfusion and BAL at day 5 after transfer and 3 days after OVA challenge in WT mice. Samples were homogenized in RIPA buffer containing protease inhibitors (50 $\mu \mathrm{g}$ total protein) and were electrophoresed on a $4-20 \%$ gradient SDS gels. Transferred PVDF membranes were probed with NF- $\kappa$ B pathway sampler kit for BM-MDRC lysates (Cell Signaling Technology, Inc, Beverly, MA) following the manufacturer's recommended dilutions. IL-33 expression in BM-MDRC lysates and lung tissue homogenates were detected using an anti-IL-33 antibody (Clone 4E9; Abcam, Cambridge, MA). Levels of $\beta$-actin, the loading control, was detected using an anti-actin antibody (Sigma, MO). 


\section{Analysis of Cytokines, IgE and Mucins}

Cytokine analysis of IL-6, TNF- $\alpha$, IL- $1 \beta$, IL-10 and IL-33 was performed on MDRC cell culture supernatants using the standard ELISA kits following the manufacturer's recommendations (R\&D systems, Minneapolis, MN and MyBioSource, Inc., San Diego, CA for IL-33). OVA-specific $\mathrm{IgE}$ was measured in the first aliquot of the BAL using ELISA following the manufacturer's recommendations (BioLegend, San Diego, CA). The levels of Muc5Ac was quantitated in the first aliquot of the BAL using ELISA following the manufacturer's recommendations (MyBioSource, Inc., San Diego, CA).

\section{Measurements of NO}

$\mathrm{NO}$ and its metabolites were measured in BM-MDRC cell culture supernatants by the Griess Assay (Cayman Chemicals, Ann Arbor, MI), which uses nitrate reductase and converts nitrate to nitrite and measures total NO production. ${ }^{32}$ Quantitation of lung cells with potential to produce NO were determined by first staining collagenaseextracted lung cells with the fluorescent indicator for NO DAF-FM-DA followed by flow cytometry as described before. $^{32}$

\section{Measurements of Superoxide}

$\mathrm{O}_{2}{ }^{\bullet-}$-producing MDRC were detected by flow cytometry after staining with myeloid cell-specific antibodies and incubating for $20 \mathrm{~min}$ at RT with dihydroxyethidium (DHE, $10 \mu \mathrm{M}$; Molecular Probes, Eugene, OR) as described before. ${ }^{32}$ The specificity of DHE for $\mathrm{O}_{2}{ }^{\bullet-}$ was validated by inducing a respiratory burst in the sorted myeloid cells by incubation at $37^{\circ} \mathrm{C}$ for $15 \mathrm{~min}$ with phorbol myristate acetate (PMA, $1 \mu \mathrm{g} / \mathrm{ml}$ ) or PMA + the NADPH oxidase inhibitor diphenylene iodonium (DPI, $1 \mu \mathrm{M}$; Tocris Bioscience, Bristol, UK), in the presence of superoxide dismutase $(256 \mathrm{mU} / \mathrm{ml}$, Sigma, St Louis, MO) or in the presence or absence of $10 \mu \mathrm{M}$ Pyrrolidine dithiocarbamate (Calbiochem, La Jolla, CA) or in the presence or absence of $5 \mu \mathrm{M}$ NF- $\kappa \mathrm{B}$ activation inhibitor II, JSH-23 (Santa Cruz Biotechnology, Santa Cruz, CA).

\section{Experimental Allergic Airway Inflammation and Intratracheal Adoptive Transfer of MDRC}

Mice were sensitized by intraperitoneal injection on $\mathrm{d} 0$ and d7 with $50 \mu \mathrm{g}$ of alum-precipitated OVA (Grade VII, Sigma Chemical, St Louis, MO; <1 ng lipopolysaccharide per $\mathrm{mg}$ ) as previously described..$^{32}$ On d $12,10^{5}$ smoke-exposed MDRC, unexposed MDRC or PBS were transferred intratracheally as described before. ${ }^{32}$ On d14, under anesthesia with isoflurane (Schering-Plough Animal Health, Union, NJ), mice were challenged i.n. with $0.03 \mathrm{ml} 0.03 \%$ OVA in PBS or PBS alone. At 3 days after challenge, bronchoalveolar lavage fluid (BAL) was collected for Muc5Ac, IL-33 and IgE analysis by ELISA. Lung tissue was homogenized for western blotting analyses, inflated and frozen (subset of animals from each experiment) and extracted with collagenase as described before ${ }^{32}$ for further analyses.

\section{Quantitation of Th1/Th2 Lymphocytes in Lung Tissue}

Immune cells were isolated as described before. ${ }^{32}$ Briefly, contamination of isolated lung cells with blood was reduced by perfusion of the pulmonary circulation with PBS via the right ventricle following euthanasia and thoracotomy. Airway lavage was performed three times with $0.8 \mathrm{ml}$ of PBS each. A 100- $\mu \mathrm{l}$ aliquot from the first collection of the return lavage fluid, after depletion of cells by centrifugation, was used for the determination of levels of cytokines. The three aliquots of lavage from each animal were pooled and used for the determination of total cell numbers and for analysis of myeloid cell subsets. The total number of viable lavage cells was determined using Trypan blue and a hemacytometer. Infiltrating leukocytes were isolated from minced lung tissue by treatment with collagenase- $\mathrm{B}(2 \mathrm{mg} / \mathrm{ml}$, Roche $)$ and DNase I $(0.02 \mathrm{mg} / \mathrm{ml}$, Sigma Chemical $)$ in Iscove's modified Dulbecco's medium (IMDM) supplemented with $1 \mathrm{mM}$ sodium pyruvate, $2 \mathrm{mM}$ L-glutamine, $10 \mu \mathrm{g} / \mathrm{ml}$ penicillinstreptomycin, $25 \mu \mathrm{M}$ 2-mercaptoethanol and $0.1 \mathrm{mM}$ nonessential amino acids (Life Technologies) at $37^{\circ} \mathrm{C}$ for $30 \mathrm{~min}$. This was followed by the addition of an equal volume of IMDM containing 20\% FBS. Cell suspensions were filtered using $40-\mu \mathrm{m}$ cell strainer, washed with PBS, treated with ACK lysis buffer (Quality Biologicals Inc., Gaithersburg, MD) and then pretreated, for $20 \mathrm{~min}$, in FACS staining buffer (PBS + 3\% FBS) containing $2.0 \mu \mathrm{g} / \mathrm{ml}$ of the mAb 2.4G2 (BD Pharmingen) at $4{ }^{\circ} \mathrm{C}$. These cells were then stained to identify and characterize immune cell populations using cell surface marker-specific fluorescence-conjugated APC-Cy7-labeled anti-CD3(Clone 17A2) and PECy-7-labeled anti-CD4 (Clone GK1.5) antibodies for $30 \mathrm{~min}$ at $4{ }^{\circ} \mathrm{C}$ (eBioscience). For detecting the frequency of IFN- $\gamma$ and IL-4-secreting cells, cells $\left(10^{6} / \mathrm{ml}\right)$ were cultured in RPMI-1640 containing $5 \mathrm{ng} /$ $\mathrm{ml}$ PMA and $500 \mathrm{ng} / \mathrm{ml}$ Ionomycin along with $10 \mu \mathrm{g} / \mathrm{ml}$ GolgiPlug protein transport inhibitor (BD Biosciences, Sparks, MD), at $37^{\circ} \mathrm{C}$, for $3 \mathrm{~h}$. Cells were then harvested, fixed and permeabilized using BD cytofix/cytoperm fixation/ permeabilization kit (BD Biosciences) and then stained with fluorescently labeled antibodies. Cells were washed twice with PBS before analysis. Flow cytometry acquisitions and analyses were carried out using Becton Dickinson LSR II with FACS Diva software (BD Biosciences, San Jose, CA). Data were further analyzed using theFlowJo 10 (Tree Star, Ashland, OR).

\section{Measurement of AHR}

Airway resistance was measured in response to increasing concentrations of inhaled aerosolized methacholine $\left(0-50 \mathrm{mg} / \mathrm{ml}\right.$ in water). ${ }^{32}$ Mice were anesthetized with ketamine $(10 \mathrm{mg} / \mathrm{kg}$ intraperitoneal) followed by pancuronium bromide $(2.0 \mathrm{mg} / \mathrm{kg})$. After insertion of an $18-\mathrm{G}$ tracheostomy catheter, the mice were mechanically ventilated 
a
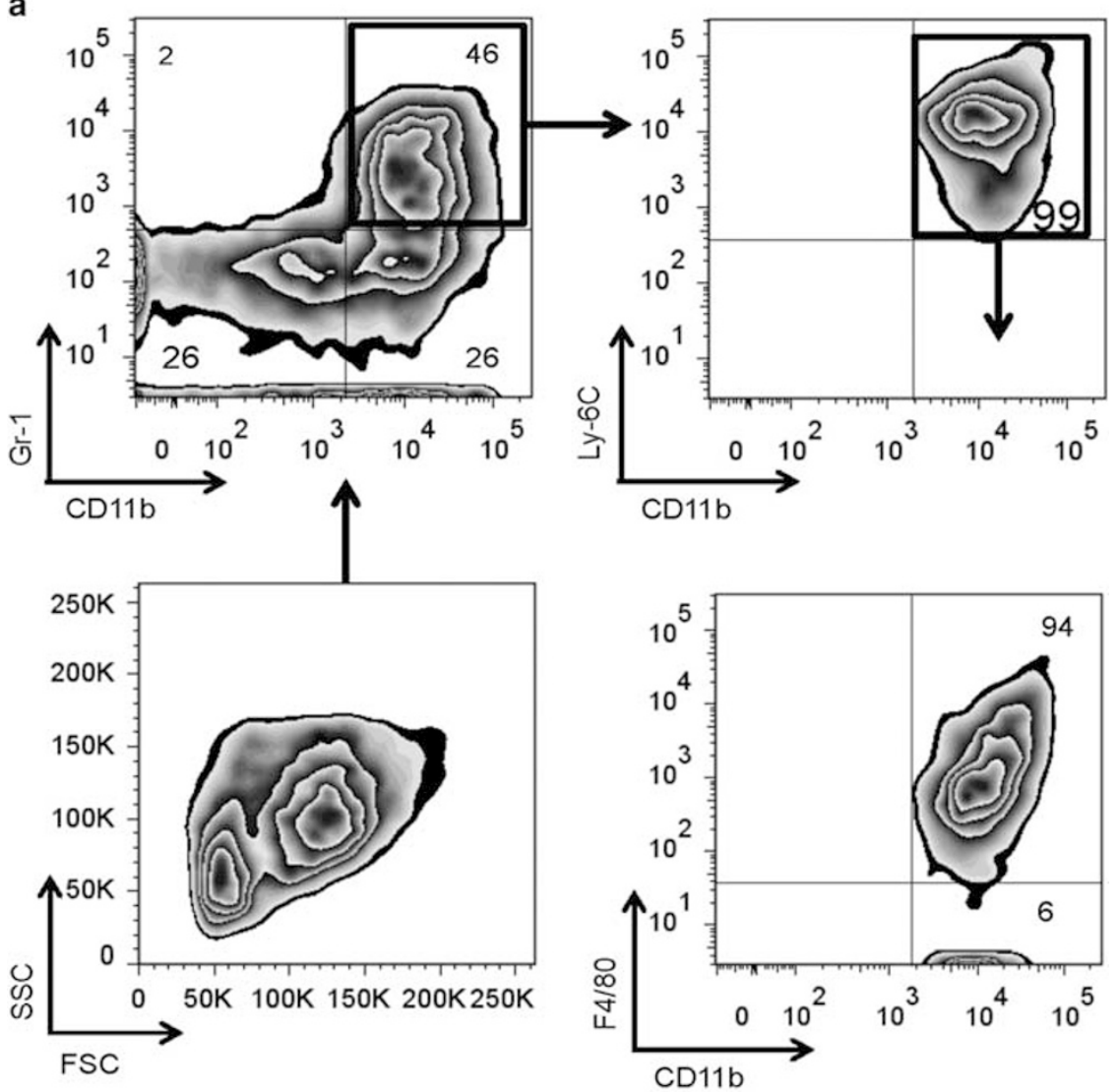

b
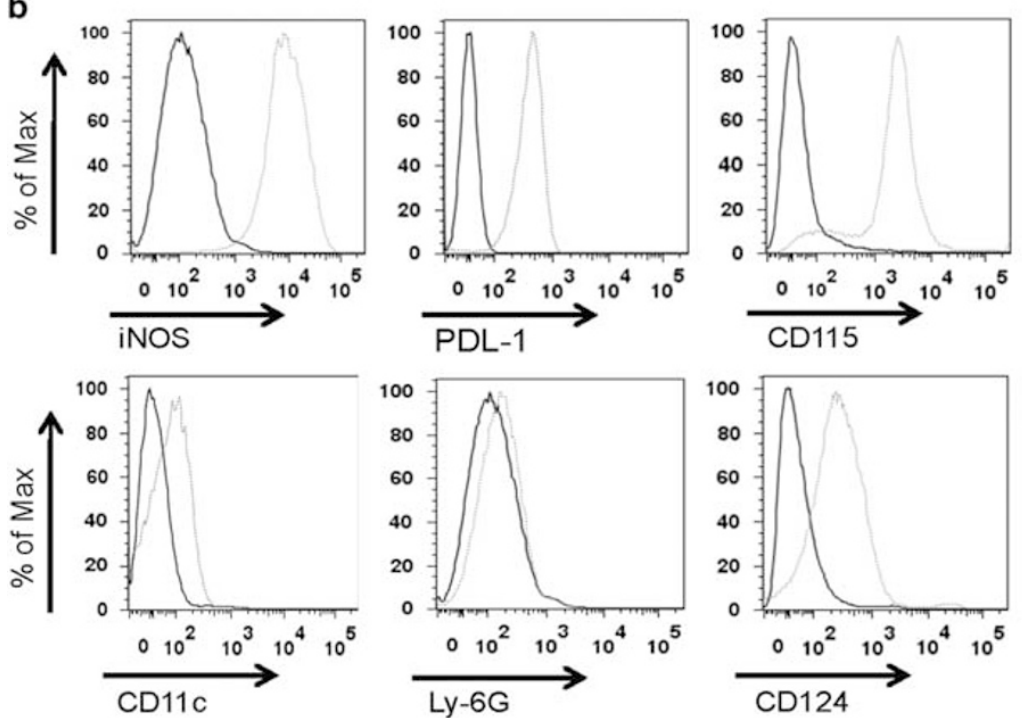

Figure 1 In vitro differentiation and characterization of $\mathrm{Ly}-6 \mathrm{C}^{+} \mathrm{MDRC}$ from bone marrow precursors. (a) Flow cytometry plots of differentiated BMMDRC showing forward and side scatter plots and the percentage of $\mathrm{Ly}-6 \mathrm{C}^{+}$and $\mathrm{F} 4 / 80^{+}$cells within the Gr-1 ${ }^{+} \mathrm{CD} 11 \mathrm{~b}^{+}$gated cells. (b) Overlaid histogram flow cytometry plots showing the levels of expression of cell surface and intracellular markers that define the phenotype of MDRC. Black lines represent isotype controls, and gray lines represent cells positive for the indicated marker.

at 160 breaths/min with a tidal volume of $0.2 \mathrm{ml}$ and a positive end-expiratory pressure of $2-4 \mathrm{~cm} \mathrm{H}_{2} \mathrm{O}$ using a flexiVent apparatus (SCIREQ, Montreal, Canada). Tissue resistance was computed continuously over the period of $20 \mathrm{~s}$ to $6 \mathrm{~min}$, and an average of 12 readings at 30-s intervals was used for calculations. 
a

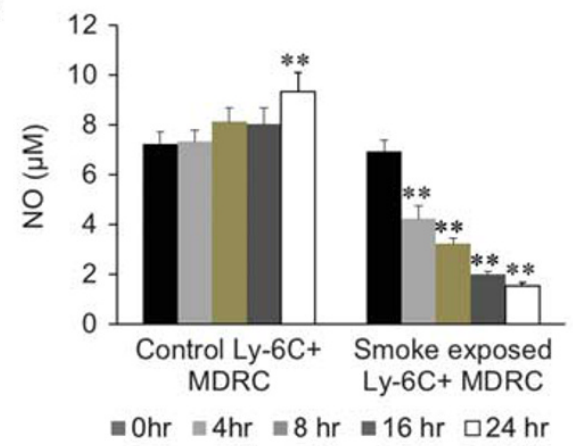

b

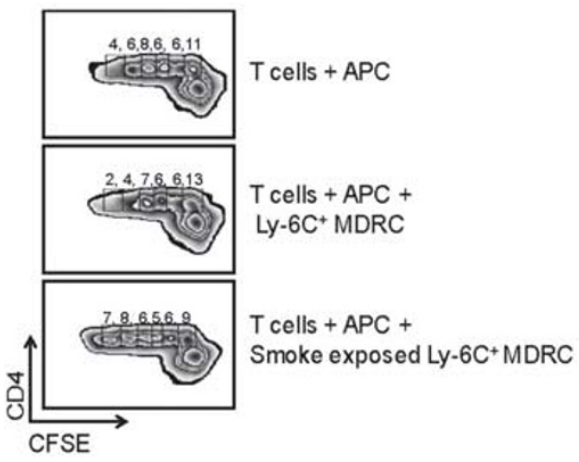

- Control

- + Ly-6C+ MDRC

- + Smoke exposed Ly-6C+ MDRC

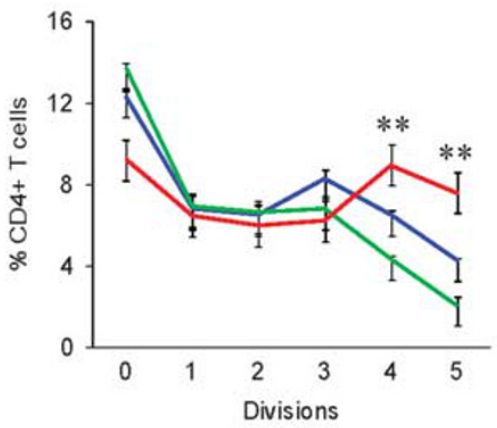

c
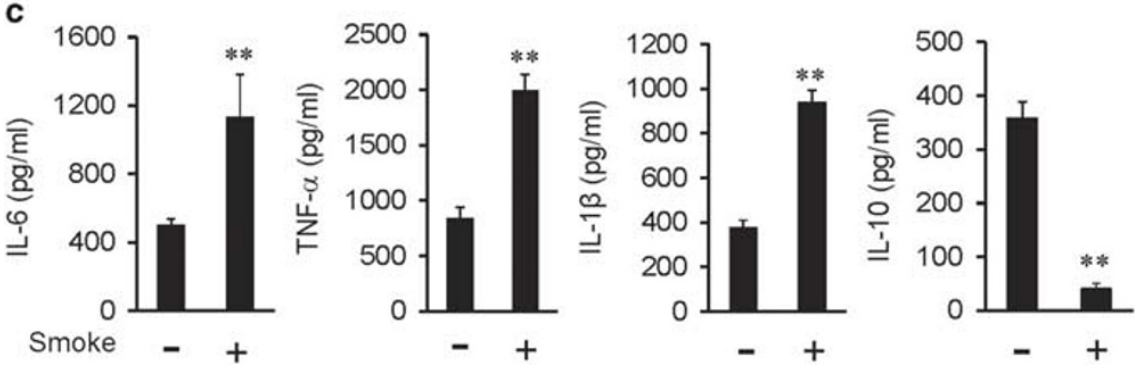

Figure 2 Cigarette smoke exposure inhibits NO production, enhances T-cell proliferation and induces a proinflammatory cytokine signature in MDRC. (a) In vitro differentiated $\mathrm{Ly}-6 \mathrm{C}^{+}$MDRC were immunosorted and were exposed to cigarette smoke as described in Materials and Methods. Cell culture supernatants were collected at $0-24 \mathrm{~h}$ after culture. Levels of nitrite and nitrate in the culture supernatants were measured in triplicates using the Griess assay. Data are mean \pm s.d., ${ }^{* *} P<0.001$ from statistical comparisons of each time point to unexposed controls using ANOVA. (b) Flow cytometry plots of CFSE-labeled $10^{5}$ OVA transgenic T cells co-cultured with $10^{5}$ CS-exposed or unexposed MDRC with $10^{4}$ BMDC pulsed with OVA peptide. CFSE dilution was assessed at $72 \mathrm{~h}$ after culture. Right panel shows flow cytometry analyses of CFSE dilution from triplicate experiments of co-cultures similar to that described in panel (b) was carried out for $n=3$ samples/group/experiment. Data are mean \pm s.d., $* * P<0.001$ in comparison of co-cultures with unsmoked MDRC vs smoked MDRC. (c) Protein levels of IL-6, TNF- $\alpha$, IL-1 $\beta$ and IL-10 in cell culture supernatants collected at $24 \mathrm{~h}$ of culture from smokeexposed and unexposed MDRC were determined by ELISA. Measurements were made from triplicate wells for each condition. Data are mean \pm s.d., representative of three independent experiments. ${ }^{* *} P<0.001$ from comparisons of unexposed vs exposed to CS.

\section{Immunofluorescence Microscopy}

Tissue sections $(6-8 \mu \mathrm{m})$ from frozen inflated lung tissue were first fixed in prechilled methanol for $10 \mathrm{~min}$ and washed with PBS followed by incubation for $1 \mathrm{~h}$ at room temperature in $1 \%$ BSA in PBS. Tissue sections were then stained with unconjugated anti-NF- $\kappa \mathrm{B}$ p65 antibody (Abcam) (diluted $1: 200$ in $1 \%$ BSA in PBS), or anti-CD33 antibody for $60 \mathrm{~min}$, at room temperature. After PBS washes, sections were incubated with Alexa594- or Alexa 488-conjugated goat anti-rabbit secondary antibody, washed in PBS and stained with DAPI. Digital photomicrographs were acquired using an Olympus BX 60 system and processed with the Adobe Photoshop software.

\section{Statistical Analysis}

Data are presented as the mean \pm s.d. Statistical analysis was performed using the Graph Pad Prizm5. One-way ANOVA with Tukey's multiple comparison posttest and the Student's $t$-test were used for comparisons. Statistical significance was determined at the $<0.05$ level. 
a

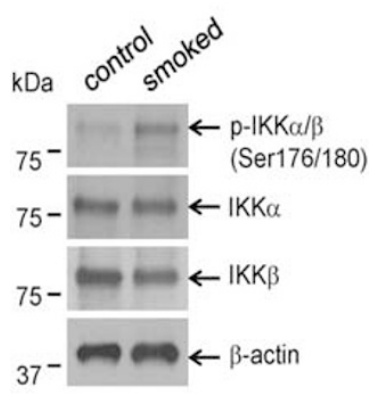

b
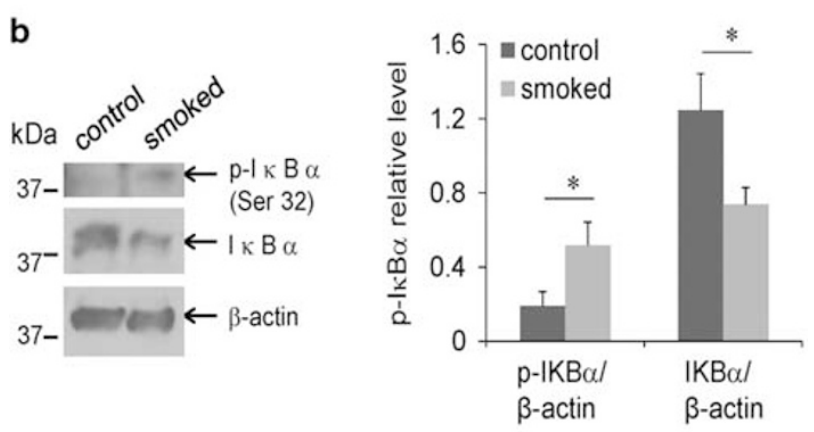

C
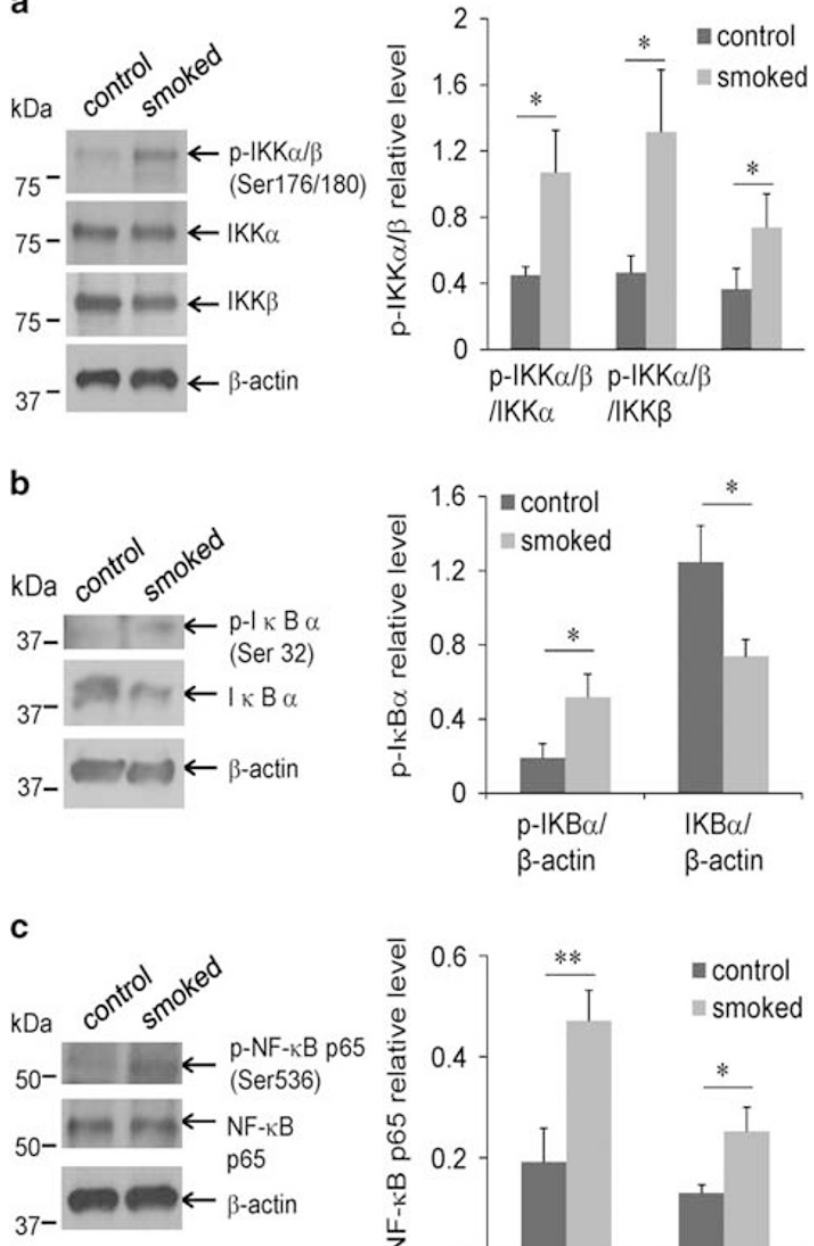

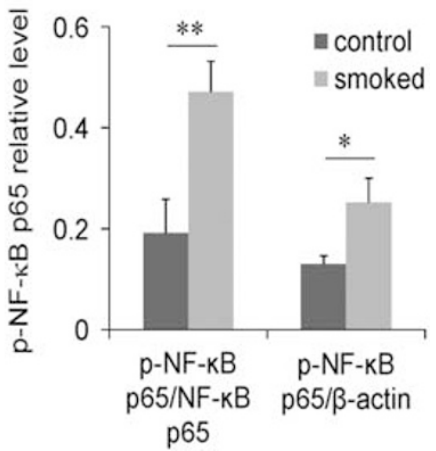

Figure 3 Cigarette smoke exposure activates NF- $\kappa$ B pathway in BM-MDRC. (a-c) Bone marrow cells were cultured in the presence of GMSCF $(10 \mathrm{ng} / \mathrm{ml})$ and LPS $(1 \mu \mathrm{g} / \mathrm{ml})$ for 7 days. Immunosorted MDRC cells were exposed to cigarette smoke as described in Materials and Methods. Western blotting analyses was carried out, and relative expression of $\mathrm{p}-\mathrm{IKK} \alpha / \beta$ vs IKK $\alpha$, IKK $\beta$ or $\beta$-actin was calculated by densitometry and quantified with the ImageJ software; relative expression of $\mathrm{p}$-IKB $\alpha$ vs $\beta$-actin and IKB $\alpha$ vs $\beta$-actin was evaluated, and the relative expression of $\mathrm{p}-\mathrm{NF}-\kappa \mathrm{B}$ p65 was normalized with NF- $\kappa \mathrm{B}$ p 65 or $\beta$-actin. Data are presented as mean \pm s.e.m. of triplicates. ${ }^{*} P<0.05$, ${ }^{* *} P<0.01$.

\section{RESULTS}

\section{Characterization of MDRC Derived from Murine BM Precursors}

In vitro culture of murine BM-derived cells with GM-CSF and LPS yielded a distinct population of differentiated Gr- ${ }^{+} \mathrm{CD}^{+} 1 \mathrm{~b}^{+}$cells, of which $99 \%$ were Ly- $6 \mathrm{C}^{+}$and $94 \%$ Ly-6C ${ }^{+}$F4/80 ${ }^{+}$(Figure 1a) as described before. ${ }^{31}$ Further analyses of surface and functional phenotype within these cells showed not only significant expression of intracellular iNOS but also showed significant expression of the IL-4 receptor $\alpha$ subunit (IL-4R $\alpha$ or CD124), which comprises part of the receptor for IL-4 and IL-13 and has been postulated as a potential marker for MDSC. ${ }^{33}$ The BM-derived MDRC (BM-MDRC) also expressed macrophage-colony stimulating factor receptor $(\mathrm{CD} 115)$ and the inhibitory $\mathrm{PD}-\mathrm{L} 1$ receptor of B7 family ${ }^{33}$ (Figure 1b). These Ly-6C ${ }^{+} \mathrm{CD} 115^{+} \mathrm{CD} 124^{+}$ $\mathrm{PDL}^{+}{ }^{+}$cells were also $\mathrm{Ly}-6 \mathrm{G}^{-} \mathrm{CD} 11 c^{\text {lo-neg }}$ and resembled the phenotype of myeloid-derived suppressor/regulatory cells described in cancer and in airway inflammation. ${ }^{34-36}$

\section{CS Exposure Inhibits NO Production and Induces a Proinflammatory Phenotype in MDRC}

We and the others demonstrated previously that $\mathrm{Gr}-1^{+}$ CD11b ${ }^{+} \mathrm{Ly}_{-6 \mathrm{C}}{ }^{+} \mathrm{F} 4 / 80^{+}$MDRC suppress T-cell proliferation and AHR. ${ }^{31,32}$ MDRC-mediated regulation of allergeninduced immune responses is mediated via iNOS-derived NO and immunoregulatory cytokines. Therefore we first investigated whether CS exposure would alter NO production by MDRC and inhibit their regulatory potential. As shown in Figure 2a, the levels of total nitrite and nitrate were significantly reduced in culture supernatants of BM-MDRC following CS exposure in a time-dependent manner without significant effects on the viability of MDRC (data not shown). Co-culture of CS-exposed BM-MDRC with CFSElabeled naive $\mathrm{CD} 4{ }^{+} \mathrm{CD} 44^{\text {lo }}$ OVA-specific $\mathrm{T}$ cells significantly increased T-cell proliferation compared with co-cultures with unsmoked MDRC in which significant T-cell suppressive effect was observed (Figure 2b). We then determined the impact of CS exposure on the cytokine profile of BM-MDRC by measuring the cytokine levels in MDRC culture supernatants following CS exposure. Significant increase in proinflammatory cytokines IL-6, TNF- $\alpha$ and IL- $1 \beta$ and reduction of immunoregulatory IL-10 was observed (Figure 2c).

\section{CS Exposure Activates NF- $\kappa$ B Pathway in BM-MDRC}

Several studies have focused on $\mathrm{NF}-\kappa \mathrm{B}$ as a central inflammatory hub that controls inflammatory processes in CS-induced chronic inflammatory lung diseases. ${ }^{37-40}$ Signaling pathways involved in oxidative stress and inflammation generally intersect with $\mathrm{NF}-\kappa \mathrm{B}$ signaling. We investigated whether CS exposure would lead to downstream activation of $\mathrm{NF}-\kappa \mathrm{B}$ signaling in BM-MDRC and modulate their function. As shown in Figure 3, CS exposure increased the phosphorylation of IKK $\alpha / \beta, \mathrm{IKB} \alpha$ and NF- $\kappa \mathrm{B}$ p 65 in BM-MDRC and decreased the expression of IKB $\alpha$ in the BM-MDRC, suggesting that $I K B \alpha$ is targeted for proteosomal degradation and indicating the activation of $\mathrm{NF}-\kappa \mathrm{B}$ pathway in BM-MDRC.

\section{Exposure to Smoke Induces MDRC-Mediated ROS Production by NF- $\kappa$ B-Dependent Mechanism}

We investigated whether CS exposure while reducing NO production by MDRC induces a proinflammatory response via ROS production. We determined ROS production from MDRC by first quantitating spectrophotometrically the 


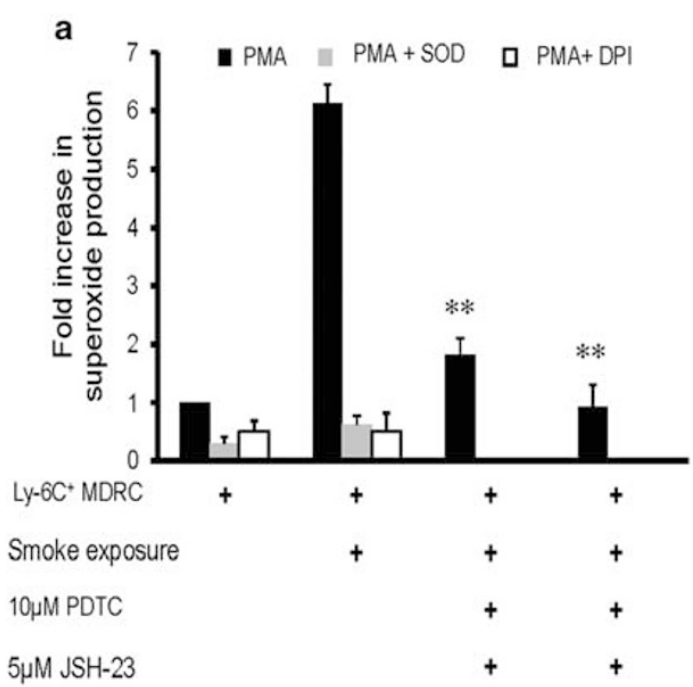

b

C
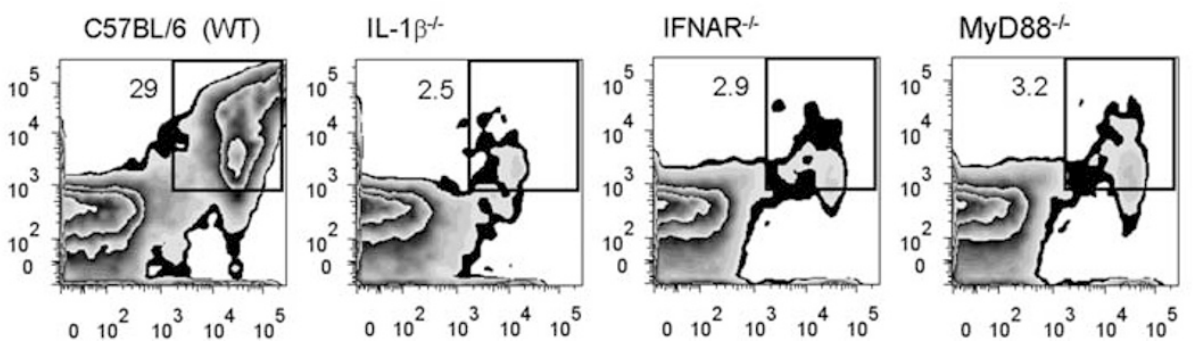

Figure 4 Cigarette smoke exposure increases superoxide production in MDRC via NF- $\kappa$ B-dependent mechanism. (a) Fold change in superoxide production was determined by spectrophotometric quantitation and monitoring of kinetics of reduction of cytochrome $c$ as described before. ${ }^{*} P<0.001$ from statistical comparisons of smoked MDRC compared with unsmoked MDRC activated by PMA in the presence or absence of PDTC (NF- $\kappa \mathrm{B}$ inhibitor) and in the presence or absence of JSH-23, an inhibitor of transcriptional activation of NF- $\kappa \mathrm{B}$ or with SOD. (b) The percentage of cells with ROS-producing potential determined by flow cytometry analyses after staining with DHE, a fluorescent indicator for ROS. (c) FACS plots showing the percentages of in vitro differentiated BM-MDRC from WT, IL-1 $\beta^{-/-}$, IFNAR ${ }^{-1-}$ and MyD88 ${ }^{-1-}$ mice. (d) Immunofluorescence analysis of lung sections showing NF- $k$ B expression in WT recipients of adoptively transferred (A) unsmoked MDRC, (B) smoked MDRC, (C) IFNAR ${ }^{-1-}$ recipients of unsmoked MDRC, (D) IFNAR ${ }^{-1-}$ recipients of smoked MDRC, (E) MyD88 ${ }^{-1-}$ recipients of unsmoked MDRC and (F) MyD88 ${ }^{-1-}$ recipients of smoked MDRC.

kinetics of reduction of cytochrome $c$ as described before. $^{32,41,42}$ Smoke exposure induced a six-fold increase in $\mathrm{O}_{2}^{\bullet-}$ production by MDRC in the presence of PMA, which was inhibited in the presence of $\mathrm{O}_{2}{ }^{\bullet-}$-quenching superoxide dismutase (SOD) or with a general NADPH oxidase inhibitor (DPI) (Figure 4a). Interestingly, this smoke-induced ROS production was inhibited in the presence of an NF- $\kappa \mathrm{B}$ inhibitor, pyrrolidine dithiocarbamate (PDTC) and NF- $\kappa \mathrm{B}$ activation inhibitor $\mathrm{JSH}-23$, suggesting a significant role for an NF- $\kappa \mathrm{B}$-dependent regulation of ROS production by BM-MDRC. Furthermore, the percentage of $\mathrm{DHE}^{+}$(fluorescent indicator for ROS) MDRC quantitated by flow cytometry was increased following smoke exposure, which was then significantly reduced in the presence of PDTC or DPI (Figure 4b).

Smoke Exposure-Mediated NF- $\kappa$ B Induction is Persistent in the Absence of Endogenous MDRC

Recent evidence suggests that TLR4/MyD88-mediated signaling and mechanisms dependent on IL-1 $\beta$ are essential for the LPS-induced generation of MDRC from BM precursors. ${ }^{31,43}$ LPS-induced signaling involves two primary pathways; a MyD88-dependent mechanism for the induction of proinflammatory cytokines and a MyD88-independent mechanism, which mediates the expression of IFN-inducible genes. ${ }^{44,45}$ Consistent with these previous studies, a significant reduction in LPS- and GM-CSF-mediated generation of BM-MDRC was observed in mice deficient in MyD88, IFN$\mathrm{AR}$ and IL-1 $\beta$, (Figure $4 \mathrm{c}$ ). Intratracheal transfer of smoked BM-MDRC into MyD88- and IFN-AR-deficient mice with reduced endogenous MDRC showed NF- $\kappa$ B activation in the airway (Figure 4d) compared with transfer recipients of unsmoked MDRC. Taken together, these data suggested prolonged induction of NF- $\kappa \mathrm{B}$ pathway in CS-exposed MDRC.

\section{Adoptive Transfer of Smoke-Exposed MDRC Enhances Allergic Airway Inflammation}

Intratracheal adoptive transfer of smoked MDRC into ovalbumin-sensitized and -challenged WT mice increased the 
d
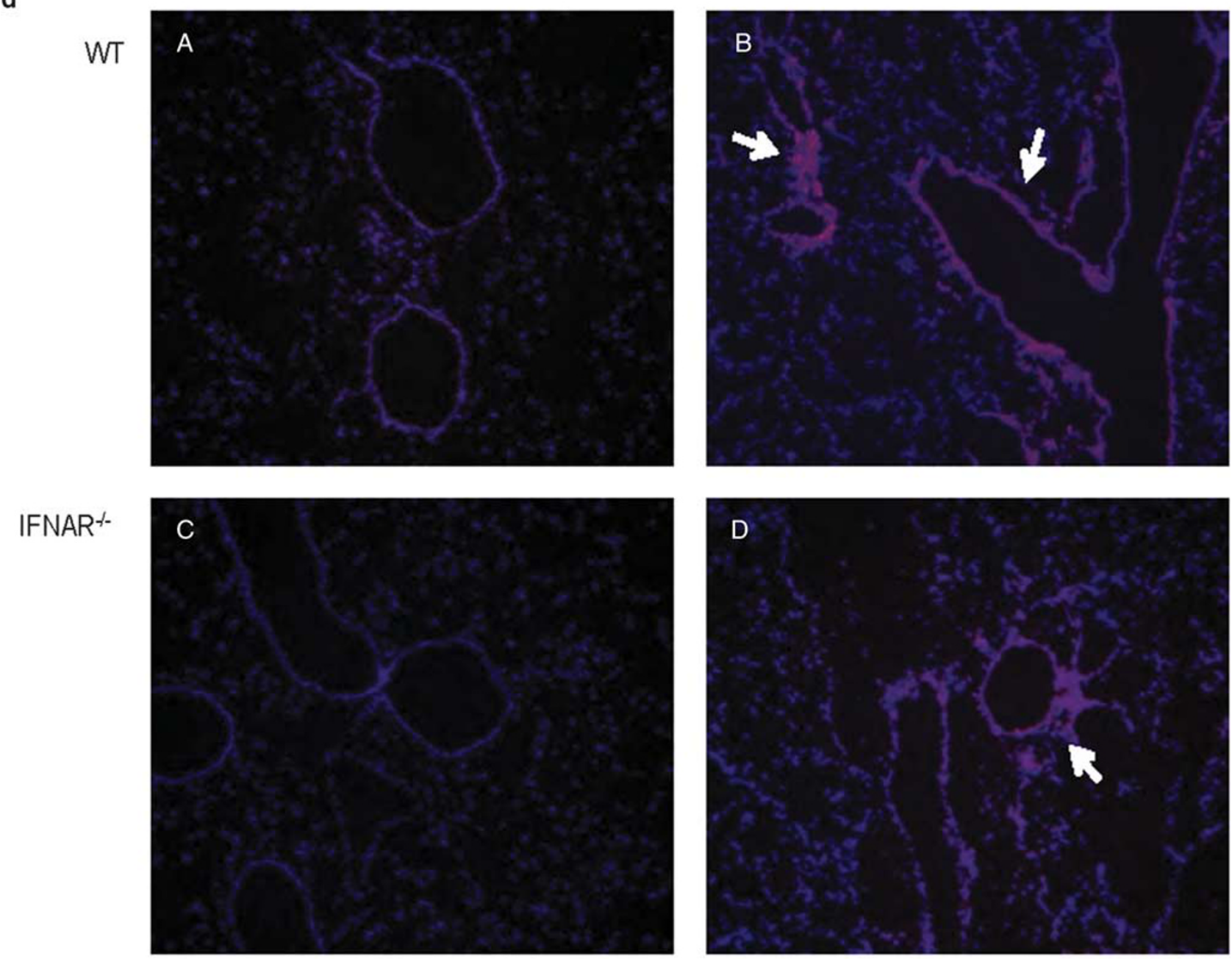

MyD88\%

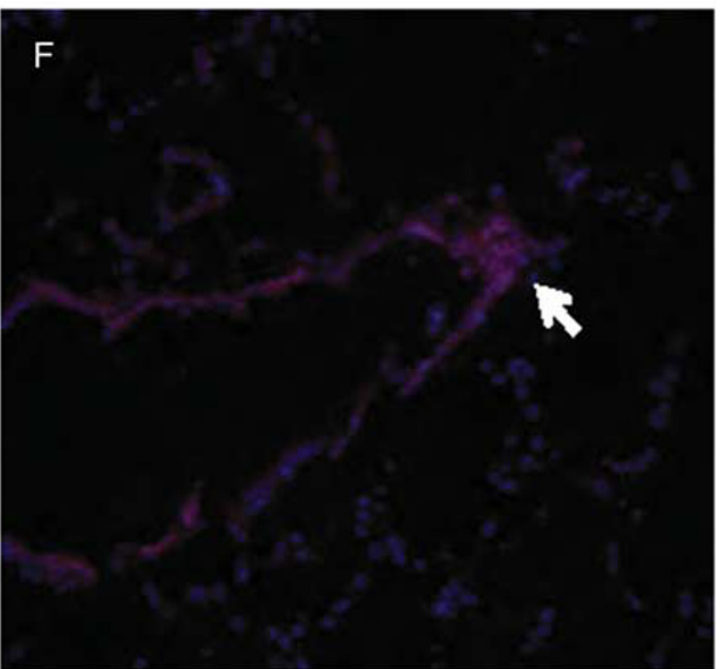

Figure 4 Continued.

percentage of $\mathrm{ROS}^{+}$cells in the lung tissue and reduced the percentage of NO-producing lung cells (Figure 5a). Total number of infiltrating total $\mathrm{CD} 4^{+}$T-cell percentages were also increased following adoptive transfer of smoked MDRC into mice with asthma. The percentages of both Th1 and Th2 lymphocytes were significantly increased, while the 

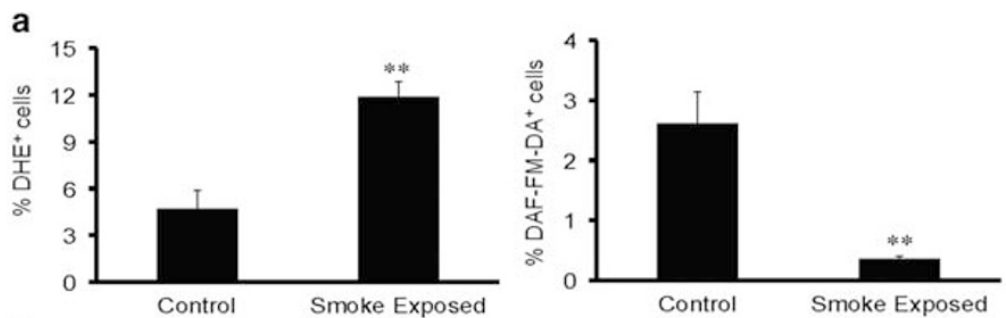

b
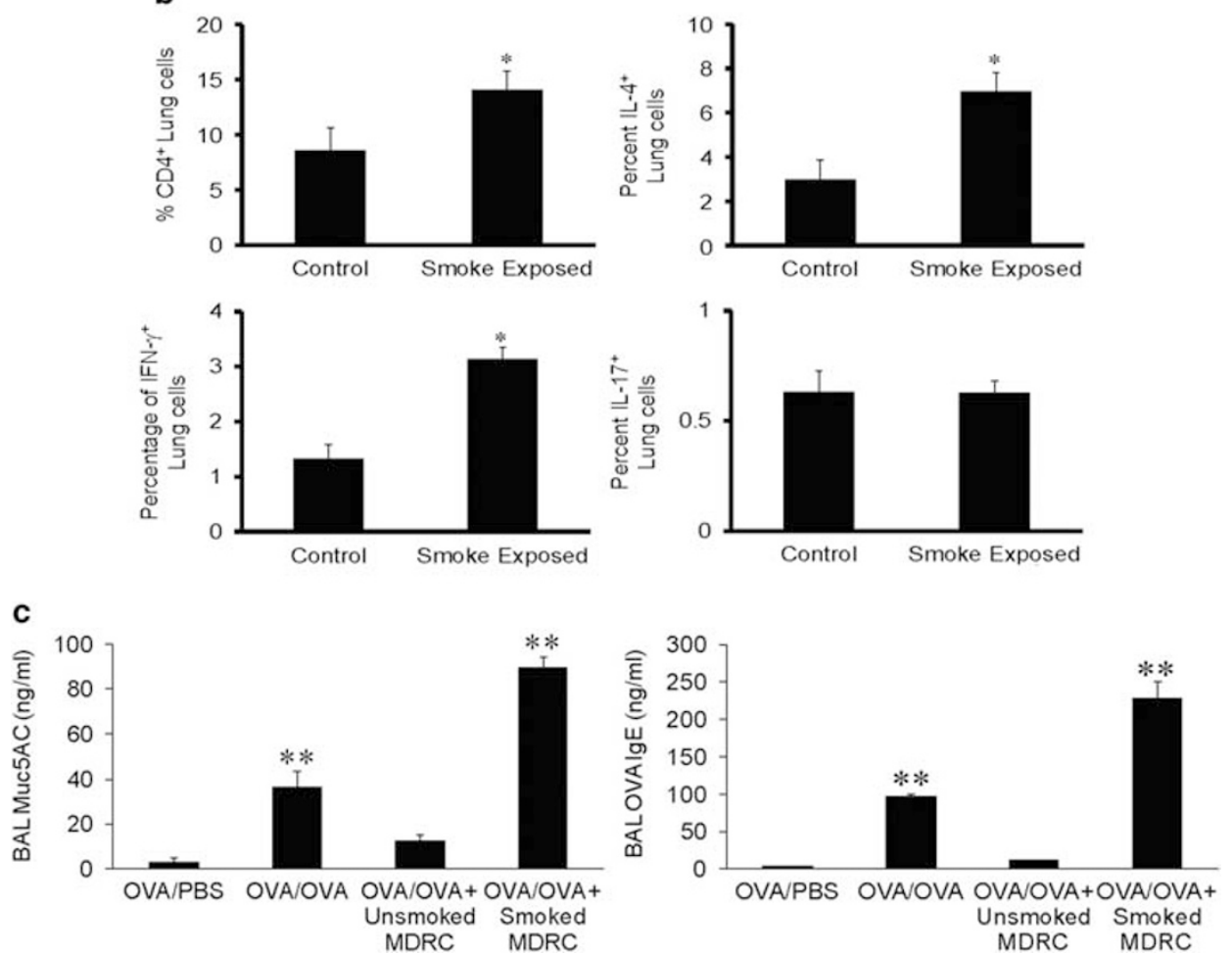

Figure 5 Intratracheal adoptive transfer of smoke-exposed MDRC enhanced Th2 responses, BAL IgE and mucin levels in vivo. (a) The percentages of lung cells producing ROS and NO were determined from collagenase-extracted immune infiltrates in lung tissue following staining with fluorescent indicators, DHE for ROS and DAF-FM-DA for NO and flow cytometry analyses. Lung tissues were harvested from mice with asthma, which were adoptive transfer recipients of either control MDRC or smoked MDRC. ${ }^{* *} P<0.001$ from statistical comparisons of adoptive transfer recipients of control vs smoked MDRC. (b) The percentages of total CD4 ${ }^{+}$T lymphocytes and subsets of Th2 (IL-4 $\left.{ }^{+}\right)$, Th1 (IFN- $\left.\gamma^{+}\right)$and Th17 (IL-17 ${ }^{+}$) in the lung tissues of mice described in panel (a) determined by flow cytometry analyses. ${ }^{*} P<0.001$ from statistical comparisons of adoptive transfer recipients of control vs smoked MDRC. (c) Left panel: Levels of Muc5Ac in BAL determined by ELISA. Data are mean \pm s.d. from $n=3$ mice/group, OVA/PBS vs OVA/OVA, OVA/OVA + smoke-exposed MDRC compared with both the OVA/OVA + unsmoked MDRC and OVA/OVA groups using ANOVA. (c) Right panel: Levels of OVA IgE in BAL determined by ELISA. Data are mean \pm s.d. from $n=3$ mice/group, ${ }^{* *} P<0.001$ from statistical comparisons of OVA/PBS vs OVA/OVA, OVA/OVA + smoke-exposed MDRC compared with both the OVA/OVA + unsmoked MDRC and OVA/OVA groups using ANOVA.

percentages of $\mathrm{CD} 4{ }^{+} \mathrm{IL}-17^{+}$remained unchanged in the adoptive transfer recipients of smoked MDRC compared with control MDRC (Figure 5b). Intratracheal transfer of unsmoked MDRCs into ovalbumin-sensitized and -challenged mice significantly inhibited airway Muc5Ac and OVA-specific IgE in the BAL (Figure 5c) compared with PBStransferred, OVA-challenged controls. The levels of Muc5Ac and OVA-IgE in OVA-challenged mice were significantly higher compared with PBS-challenged controls. Importantly, intratracheal adoptive transfer of smoke-exposed MDRC enhanced Muc5Ac and OVA-IgE in OVA-challenged mice, the levels of which were significantly higher than detected in transfer recipients of unsmoked MDRC.
Adoptive Transfer of Smoke-Exposed MDRC Enhances
IL-33 Production in the Airways and Lungs of Mice with
Allergic Airway Inflammation
IL-33 is a pleiotropic cytokine predominantly expressed in lung tissue and can elicit airway inflammation in mice. ${ }^{25} \mathrm{We}$ tested the hypothesis that IL-33 is induced by CS and contribute to CS-mediated exacerbation of airway inflammation. We first determined the expression in BM-MDRC, which was significantly increased after CS exposure (Figure 6a). We also observed increased levels of IL-33 in the lung tissues of mice following adoptive transfer of smoked MDRC compared with control MDRC (Figure 6b). We then compared the levels of IL-33 in the BAL of mice sensitized and/or challenged with 
a

Ly-6C+MDRC

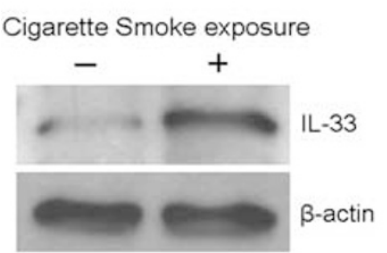

b

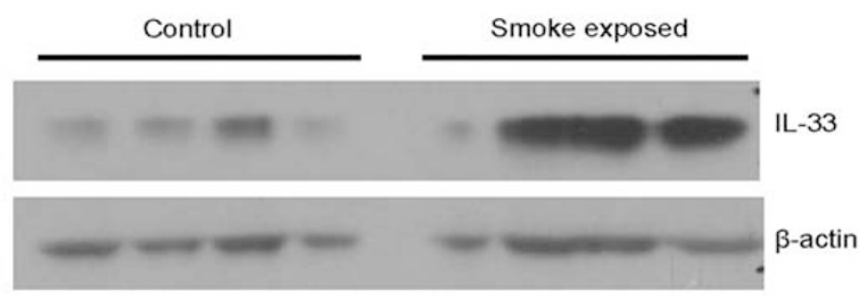

C

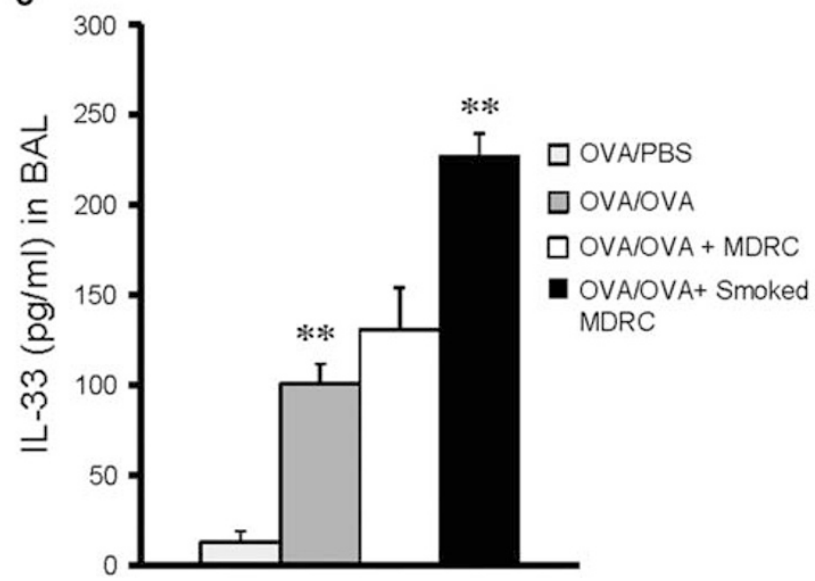

Figure 6 Smoke exposure promotes IL-33 production in MDRC in vitro and in vivo. (a) Western blotting of control and smoke-exposed BM-MDRC probed with anti-IL-33 and anti- $\beta$ actin antibodies showing increased IL-33 expression after CS exposure. (b) Western blotting analyses of perfused lung tissue samples of ovalbumin-sensitized wild-type C57BL/6 mice harvested at day 5 after intratracheal transfer of control and smoke-exposed BM-MDRC and 3 days after intranasal ovalbumin challenge probed with anti-IL-33 and anti- $\beta$ actin antibodies showing increased IL-33 expression after CS exposure. (c) Levels of IL-33 detected by ELISA in BAL fluid harvested at 5 days after adoptive transfer and 3 days after ovalbumin or PBS challenge from adoptive transfer recipients of unsmoked and smoked MDRC compared with controls. ${ }^{* *} P<0.01$ compared with controls. (d) Immunofluorescence analysis of lung sections harvested at 5 days after adoptive transfer and 3 days after ovalbumin challenge showing IL-33 expression in (A) WT ovalbumin-sensitized mice, (B) WT ovalbumin-sensitized and -challenged mice and WT ovalbumin-sensitized and -challenged mice that are recipients of adoptively transferred (C) unsmoked MDRC and (D) smoked MDRC.

OVA before and after transfer of smoked or control MDRC. As shown in Figure 6c, IL-33 levels were increased in BAL of mice with asthma compared with PBS-sensitized mice. Adoptive transfer of control MDRC did not alter the IL-33 levels in BAL but transfer of smoked MDRC significantly enhanced the BAL levels of IL-33. Additionally, we detected an increase in $\mathrm{IL}_{-} 33^{+}$cells in vivo 5 days after adoptive transfer and 3 days after antigen challenge in the lung tissue of adoptive transfer recipients of smoked MDRC compared with control MDRC-recipient mice (Figure 6d).

\section{Adoptive Transfer of Smoke-Exposed MDRC Exacerbates AHR}

We then investigated the impact of smoke exposure on the potential of MDRC to regulate AHR. As shown in Figure 7, WT mice induced with asthma and which were recipients of smoked MDRC had significantly higher airway resistance compared with recipients of unsmoked MDRC and PBS. We then determined AHR in both IFN-AR- and MyD88-deficient mice following intratracheal adoptive transfer of smoked and unsmoked MDRC and compared with controls within these groups of mice. Although a robust dose-dependent response to methacholine challenge was not observed in both MyD88and IFN-AR-deficient mice, a significant increase in AHR was noted following transfer of smoked MDRC compared with unsmoked and PBS controls. Thus these studies suggest that smoke exposure switches MDRC from an anti-inflammatory to a significantly proinflammatory functional phenotype, which produces ROS via an NF- $\kappa \mathrm{B}$-dependent mechanism and exacerbates allergic airway inflammation.

\section{DISCUSSION}

In this study, we provide evidence that exposure to CS has a significant impact on MDRC-mediated regulation of allergic airway inflammation. CS-exposed MDRC showed reduced activation of iNOS resulting in the reduction of metabolites of NO. Additionally, the enhancement of a proinflammatory cytokine signature, including IL-1 family member IL-33 and TNF- $\alpha$, and inhibition of IL-10-mediated effects was induced upon exposure to CS in vitro. Importantly, CS altered the 

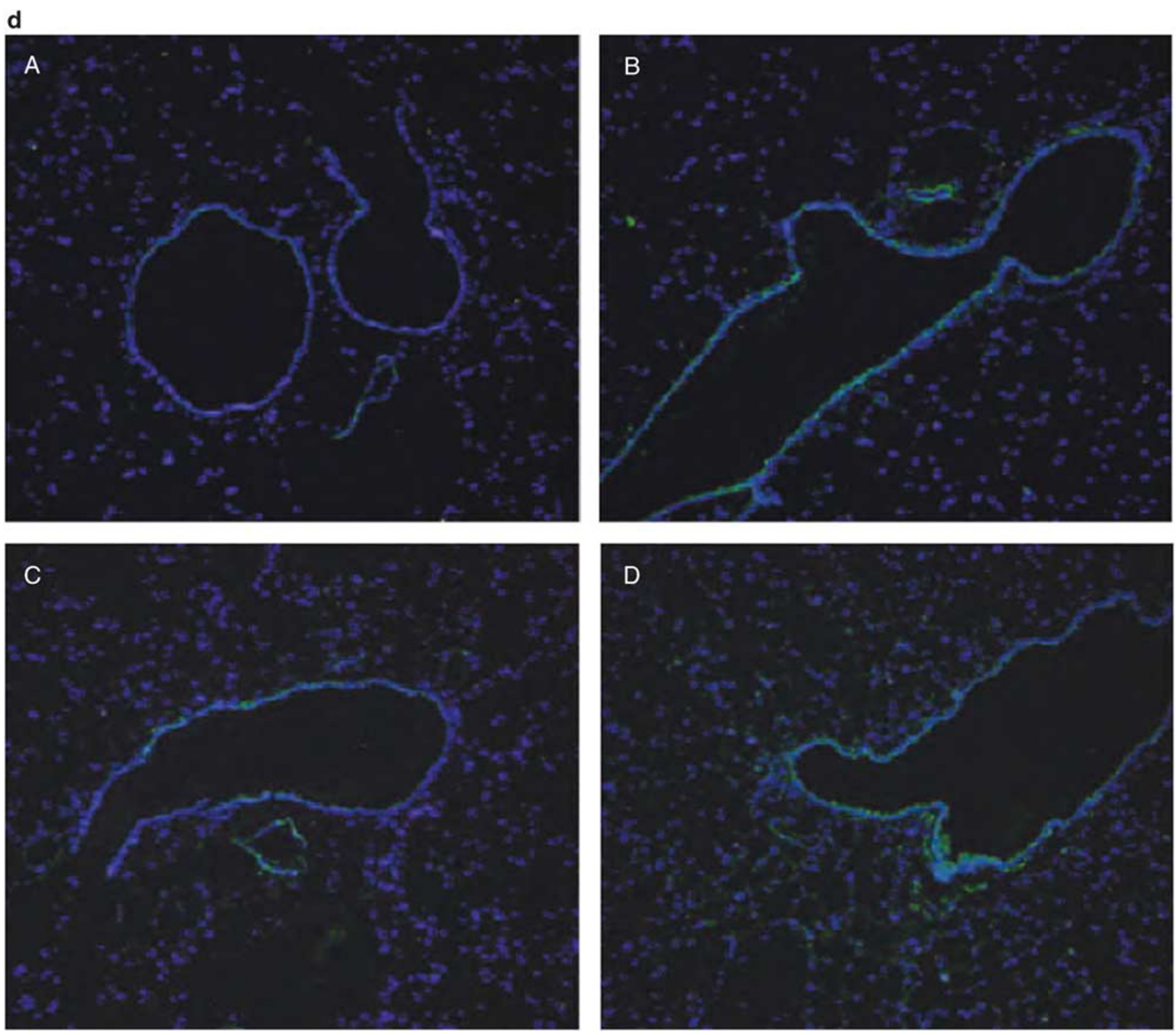

Figure 6 Continued.

immunesuppressive MDRC and switched them to a NADPH oxidase-mediated ROS-producing proinflammatory functional phenotype by persistent activation of NF- $\kappa$ B-dependent mechanism, which contributed to exacerbation of AHR and an increase in overall allergic airway inflammation.

Ample evidence supports an oxidant-antioxidant imbalance in asthma. Overabundance of oxidants from environmental contributions and antigen exposure burdens our antioxidant defense systems causing this imbalance. Antioxidant enzymatic mechanisms, including superoxide dismutases (SOD), are reduced in asthmatics, aggravating this oxidant-antioxidant imbalance. Exposure to CS enhances this oxidative stress associated with asthma. CS directly generates oxidants and activates cellular sources to generate more oxidants to further aggravate this oxidant-antioxidant balance. Our observation that CS alters the ROS production by MDRC and induces the phenotypic switch to a proinflammatory MDRC is consistent with the impact that CS and oxidants can exert on myeloid-cell lineages. Although direct effects of CS on innate immune mechanisms that regulate airway inflammation have not been well characterized, recent evidence suggest that CS may primarily trigger IL-33 production that stimulates the synthesis of further key proinflammatory cytokines, chemokines and other inflammatory mediators in the airway. ${ }^{22,23}$ Our data presented here clearly suggests a role for CS in impacting molecular mediators and downstream signaling cascades of innate immune pathways of MDRC, including IL-33 and NF- $\kappa \mathrm{B}$ signaling, to regulate allergic airway inflammation and AHR. IL-33 participates in immuneregulation and inflammation by signaling through 

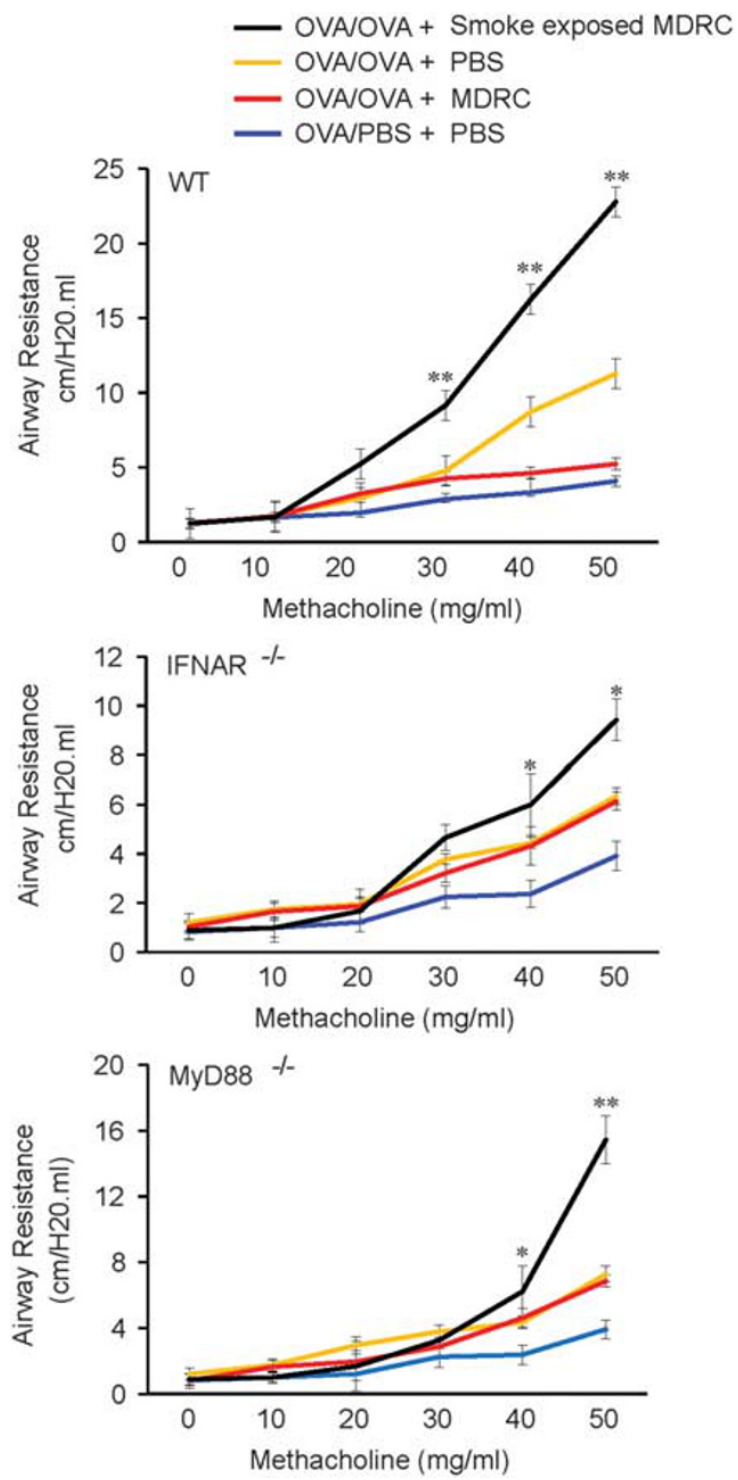

Figure 7 Intratracheal adoptive transfer of CS-exposed MDRC exacerbates airway hyper-responsiveness in antigen-challenged mice with asthma. Change in airway resistance was measured using flexiVent in OVA-sensitized mice at Day3 after intranasal challenge with OVA (5 days after intratracheal transfer of smoke-exposed and unexposed MDRC) in $n=6-8$ animals/group for OVA/PBS (OVA-sensitized and PBS-challenged mice), OVA/OVA + PBS (OVA-sensitized and OVA-challenged with intratracheal transfer of PBS), OVA/OVA + MDRC (OVA-sensitized and OVA-challenged with intratracheal transfer of unsmoked MDRC) and OVA/OVA + smoke-exposed MDRC (OVA-sensitized and OVA-challenged with intratracheal transfer of smoked MDRC). ${ }^{* *} P<0.01$ in comparison with transfer of unsmoked MDRC and controls, ${ }^{*} P<0.05$ in comparison with adoptive transfer of unsmoked MDRC and controls.

Toll-like receptor pathways involving My-D88, leading to activation of NF- $\kappa \mathrm{B}$ which then drives the transcription of proinflammatory genes that activate enzymatic pathways leading to oxidative stress. ${ }^{24,46-48}$ Our observations with

IL-33 induction in smoke-exposed MDRC both in vitro and in vivo are consistent with the potential of CS in inducing activation of downstream signaling cascades via IL-33.

MDRC subsets have been appreciated as critical regulators of airway inflammation. Recent studies have highlighted the significance of plasticity of the different subsets that drive their differential functions/molecular mechanisms to regulate dysregulated immune responses. Altered inflammatory responses of alveolar macrophages (AM) to cigarette smoking have been implicated in the pathological changes leading to chronic lung diseases. ${ }^{49,50}$ Deactivation of steady-state polarization of AMs from M1 phenotype to an unusual M2-like polarization has been reported in healthy smokers. ${ }^{51}$ This reprogramming of macrophage polarization was even more progressive in subjects with chronic obstructive pulmonary disease, with a progressive deactivation of M1 gene expression and progressive induction of M2 phenotype that was quite distinct from healthy smokers. ${ }^{51}$ Exposure studies investigating macrophage activation by ambient air pollution particulates, including superparamagnetic iron oxide, showed suppression of IL-10 production and enhanced TNF- $\alpha$ production with an impaired ability to make M1-M2 phenotype transitions. ${ }^{52}$ The CS-induced plasticity in MDRC function that we are reporting here are thus consistent with the environmental pollution-mediated transcriptional reprogramming of macrophage function reported in these studies. Our studies suggest that CS and its components have a direct effect on the molecular mediators and functional plasticity of MDRC. Our studies also demonstrate a direct inhibitory effect of CS on the immune-suppressive mechanisms of MDRC. ROS production that ensued from either the CS-induced oxidant-antioxidant imbalance or activation of $\mathrm{NF} \kappa \mathrm{B}$ pathway dictated the phenotypic plasticity/maturation of MDRC, rendering them proinflammatory and providing them the potential to enhance T-cell-driven inflammation as well as airway responses. This proinflammatory switch of MDRC function was inhibited by blocking downstream NF- $\kappa \mathrm{B}$ signaling cascades, suggesting once again the significance of redoxmediated signaling in regulation of immune mechanisms.

We demonstrate here that CS enhances MDRC-mediated production of IL-33. IL-33 has long been known to signal via the IL-1 receptor-related protein ST-2 and to induce Th2 responses. ${ }^{24}$ IL-33 is also a transcriptional regulator and activator of $\mathrm{NF} \kappa \mathrm{B}$ pathway. ${ }^{47}$ Our data suggest that CS exposure promotes IL-33 production by MDRC and induces ROS production via $\mathrm{NF} \kappa \mathrm{B}$ pathway and leads to Th2 responses. Our studies, however, do not delineate whether smoke exposure-mediated IL-33 induction and downstream activation of NF- $\kappa \mathrm{B}$ leads to induction of proinflammatory genes that activates ROS and drives further IL-33 production in a feed-back mechanism. It remains to be determined whether CS exposure and IL-33-mediated mechanisms would inhibit the potential of MDRC in inducing differentiation/ recruitment of regulatory $\mathrm{T}$ cells in vivo. 
Our studies also indicate a role for CS-mediated modulation of these signaling cascades in driving the uncontrolled proliferative response of $\mathrm{T}$ cells and airway exacerbations. Although cigarette smoking causes a systemic inflammatory response, inhibition of T-cell-mediated responses that drive lung diseases are consistent with exposure to high doses of CS with reductions in Th2 cell infiltration, Th2 cytokine production and reduced eosinophilia. ${ }^{53}$ Low-dose exposure does not promote this suppressive response. Although transition from the oxidative burst response phase of the M1 phenotype to the sensitization phase favoring the M2 phenotype occurs also with chronic exposure to smoke, loss of T-cell function and the associated reduction in Th2 cytokine production may impact the M2 transition. This may result in the progressive induction of IgE-producing Th2 response with M2 phenotype but with suppression of atopic inflammatory response. Our studies are more in line with a low-dose chronic CS exposure or acute CS exposure rather than a chronic elevated-dose CS exposure in which asthmatic response is suppressed despite sensitization. Although MDRC subsets exhibit overlapping M1 and M2 features, our data suggest that CS exposure induces polarization of MDRC resembling M1 to M2 transitions. Future studies are warranted to address a potential dosedependent CS-mediated induction of plasticity in MDRC. Our studies thus identify new molecular pathways to target MDRC function and MDRC-mediated regulation of airway inflammation.

\section{ACKNOWLEDGMENTS}

We thank Marion Spell (Center for AIDS Research Flow Facility Core for cell sorting) for technical support for Fluorescent Activated Cell Sorting. This study was supported by the Young Clinical Scientist Faculty Award of the Flight Attendants Medical Research Institute awarded to JSD. Part of this work is supported by the National Institutes of Health Grants Al076389 to AJCS. AJCS is a Burroughs Welcome Investigator in the Pathogenesis of Infectious Diseases.

\section{DISCLOSURE/CONFLICT OF INTEREST}

The authors declare no conflict of interest.

1. Djukanovic R, Roche WR, Wilson JW, et al. Mucosal inflammation in asthma. Am Rev Respir Dis 1990;142:434-457.

2. Boushey HA, Fahy JV. Basic mechanisms of asthma. Environ Health Perspect 1995;103(Suppl 6):229-233.

3. Eisenbarth SC, Cassel S, Bottomly K. Understanding asthma pathogenesis: linking innate and adaptive immunity. Curr Opin Pediatr 2004;16:659-666.

4. Fernandes PD, Landgraf RG, Britto LR, et al. Production of nitric oxide by airways neutrophils in the initial phase of murine asthma. Int Immunopharmacol 2007;7:96-102.

5. Schroder NW, Maurer M. The role of innate immunity in asthma: leads and lessons from mouse models. Allergy 2007;62:579-590.

6. Walters $\mathrm{EH}$, Wood-Baker $\mathrm{R}$, Reid $\mathrm{DE}$, et al. Innate immune activation in neutrophilic asthma. Thorax 2008;63:88-89.

7. Calhoun WJ, Reed HE, Moest DR, et al. Enhanced superoxide production by alveolar macrophages and air-space cells, airway inflammation, and alveolar macrophage density changes after segmental antigen bronchoprovocation in allergic subjects. Am Rev Respir Dis 1992;145:317-325.
8. Dupont LJ, Rochette F, Demedts MG, et al. Exhaled nitric oxide correlates with airway hyperresponsiveness in steroid-naive patients with mild asthma. Am J Respir Crit Care Med 1998;157:894-898.

9. Henricks PA, Nijkamp FP. Reactive oxygen species as mediators in asthma. Pulm Pharmacol Ther 2001;14:409-420.

10. Mathrani VC, Kenyon NJ, Zeki A, et al. Mouse models of asthma: can they give us mechanistic insights into the role of nitric oxide? Curr Med Chem 2007;14:2204-2213.

11. Rothenberg ME, Doepker MP, Lewkowich IP, et al. Cationic amino acid transporter 2 regulates inflammatory homeostasis in the lung. Proc Natl Acad Sci USA 2006;103:14895-14900.

12. Zimmermann N, Rothenberg ME. The arginine-arginase balance in asthma and lung inflammation. Eur J Pharmacol 2006;533:253-262.

13. Eisner MD. Environmental tobacco smoke and adult asthma. Exp Lung Res 2005;31(Suppl 1):8-14.

14. Eisner MD, Klein J, Hammond SK, et al. Directly measured second hand smoke exposure and asthma health outcomes. Thorax 2005;60:814-821.

15. Seymour BW, Schelegle ES, Pinkerton KE, et al. Second-hand smoke increases bronchial hyperreactivity and eosinophilia in a murine model of allergic aspergillosis. Clin Dev Immunol 2003;10:35-42.

16. Seymour BW, Pinkerton KE, Friebertshauser KE, et al. Second-hand smoke is an adjuvant for T helper-2 responses in a murine model of allergy. J Immunol 1997;159:6169-6175.

17. Woodruff $\mathrm{PG}$, Koth $\mathrm{LL}$, Yang $\mathrm{YH}$, et al. A distinctive alveolar macrophage activation state induced by cigarette smoking. Am J Respir Crit Care Med 2005;172:1383-1392.

18. Maniscalco M, Di Mauro V, Farinaro E, et al. Transient decrease of exhaled nitric oxide after acute exposure to passive smoke in healthy subjects. Arch Environ Health 2002;57:437-440.

19. Maniscalco M, Vatrella A, Sofia M. Passive smoke and exhaled nitric oxide. Am J Respir Crit Care Med 2002;165:1188author reply 1188.

20. Tsuchiya M, Asada A, Kasahara E, et al. Smoking a single cigarette rapidly reduces combined concentrations of nitrate and nitrite and concentrations of antioxidants in plasma. Circulation 2002;105: $1155-1157$.

21. Horvath I, Donnelly LE, Kiss A, et al. Exhaled nitric oxide and hydrogen peroxide concentrations in asthmatic smokers. Respiration 2004; 71:463-468.

22. Qiu C, Li Y, Li M, et al. Anti-interleukin-33 inhibits cigarette smokeinduced lung inflammation in mice. Immunology 2013;138:76-82.

23. Wu H, Yang $\mathrm{S}, \mathrm{Wu} X$, et al. Interleukin-33/ST2 signaling promotes production of interleukin- 6 and interleukin-8 in systemic inflammation in cigarette smoke-induced chronic obstructive pulmonary disease mice. Biochem Biophys Res Commun 2014;450:110-116.

24. Schmitz J, Owyang A, Oldham E, et al. IL-33, an interleukin-1-like cytokine that signals via the IL-1 receptor-related protein ST2 and induces T helper type 2-associated cytokines. Immunity 2005;23: 479-490.

25. Liew FY, Pitman NI, McInnes IB. Disease-associated functions of IL-33: the new kid in the IL-1 family. Nat Rev. Immunol 2010;10:103-110.

26. Kurowska-Stolarska M, Stolarski B, Kewin P, et al. IL-33 amplifies the polarization of alternatively activated macrophages that contribute to airway inflammation. J Immunol 2009;183:6469-6477.

27. Guo Z, Wu J, Zhao J, et al. IL-33 promotes airway remodeling and is a marker of asthma disease severity. J Asthma 2014;51:1-7.

28. Farahani R, Sherkat R, Hakemi MG, et al. Cytokines (interleukin-9, IL-17, IL-22, IL-25 and IL-33) and asthma. Adv Biomed Res 2014;3:127.

29. Kharitonov SA, Robbins RA, Yates D, et al. Acute and chronic effects of cigarette smoking on exhaled nitric oxide. Am J Respir Crit Care Med 1995;152:609-612.

30. Nadif R, Matran R, Maccario J, et al. Passive and active smoking and exhaled nitric oxide levels according to asthma and atopy in adults. Ann Allergy Asthma Immunol 2010;104:385-393.

31. Arora M, Poe SL, Oriss TB, et al. TLR4/MyD88-induced CD11b + Gr-1 int $\mathrm{F} 4 / 80+$ non-migratory myeloid cells suppress Th2 effector function in the lung. Mucosal Immunol 2010;3:578-593.

32. Deshane J, Zmijewski JW, Luther $\mathrm{R}$, et al. Free radical-producing myeloid-derived regulatory cells: potent activators and suppressors of lung inflammation and airway hyperresponsiveness. Mucosal Immunol 2011;4:503-518.

33. Mandruzzato $\mathrm{S}$, Solito $\mathrm{S}$, Falisi $\mathrm{E}$, et al. IL4Ralpha + myeloid-derived suppressor cell expansion in cancer patients. J Immunol 2009;182: 6562-6568. 
34. Gabrilovich DI, Nagaraj S. Myeloid-derived suppressor cells as regulators of the immune system. Nat Rev Immunol 2009;9:162-174.

35. Gabrilovich DI, Ostrand-Rosenberg S, Bronte V. Coordinated regulation of myeloid cells by tumours. Nat Rev Immunol 2012;12:253-268.

36. Nagaraj S, Collazo M, Corzo CA, et al. Regulatory myeloid suppressor cells in health and disease. Cancer Res 2009;69:7503-7506.

37. Caramori G, Romagnoli M, Casolari $\mathrm{P}$, et al. Nuclear localisation of p65 in sputum macrophages but not in sputum neutrophils during COPD exacerbations. Thorax 2003;58:348-351.

38. Di Stefano A, Caramori G, Oates $T$, et al. Increased expression of nuclear factor-kappaB in bronchial biopsies from smokers and patients with COPD. Eur Respir J 2002;20:556-563.

39. Szulakowski $P$, Crowther AJ, Jiménez LA, et al. The effect of smoking on the transcriptional regulation of lung inflammation in patients with chronic obstructive pulmonary disease. Am J Respir Crit Care Med 2006;174:41-50.

40. Bonizzi G, Karin M. The two NF-kappaB activation pathways and their role in innate and adaptive immunity. Trends Immunol 2004;25:280-288.

41. Fridovich I. Superoxide dismutases. Adv Enzymol Relat Areas Mol Biol 1986;58:61-97.

42. Fridovich I, Freeman B. Antioxidant defenses in the lung. Annu Rev Physiol 1986;48:693-702.

43. Arora M, Poe SL, Ray A, et al. LPS-induced CD11b + Gr1(int)F4/80 + regulatory myeloid cells suppress allergen-induced airway inflammation. Int Immunopharmacol 2011;11:827-832.

44. Baccala $\mathrm{R}$, Hoebe $\mathrm{K}$, Kono $\mathrm{DH}$, et al. TLR-dependent and TLRindependent pathways of type I interferon induction in systemic autoimmunity. Nat Med 2007;13:543-551.
45. Khoo J, Forster S, Mansell A. Toll-like receptors as interferonregulated genes and their role in disease. J Interferon Cytokine Res 2011;31:13-25

46. $\mathrm{Na} \mathrm{HJ}$, Hudson SA, Bochner BS. IL-33 enhances Siglec-8 mediated apoptosis of human eosinophils. Cytokine 2012;57: 169-174.

47. Choi YS, Park JA, Kim J, et al. Nuclear IL-33 is a transcriptional regulator of NF-kappaB p65 and induces endothelial cell activation. Biochem Biophys Res Commun 2012;421:305-311.

48. Bouffi $C$, Rochman $M$, Zust CB, et al. IL-33 markedly activates murine eosinophils by an NF-kappaB-dependent mechanism differentially dependent upon an IL-4-driven autoinflammatory loop. J Immunol 2013;191:4317-4325.

49. Barnes PJ. The cytokine network in asthma and chronic obstructive pulmonary disease. J Clin Invest 2008;118:3546-3556.

50. Barnes PJ. Immunology of asthma and chronic obstructive pulmonary disease. Nat Rev Immunol 2008;8:183-192.

51. Shaykhiev R, Krause A, Salit J, et al. Smoking-dependent reprogramming of alveolar macrophage polarization: implication for pathogenesis of chronic obstructive pulmonary disease. J Immunol 2009;183:2867-2883.

52. Kodali V, Littke $\mathrm{MH}$, Tilton SC, et al. Dysregulation of macrophage activation profiles by engineered nanoparticles. ACS Nano 2013;7 6997-7010.

53. Thatcher TH, Benson RP, Phipps RP, et al. High-dose but not low-dose mainstream cigarette smoke suppresses allergic airway inflammation by inhibiting $\mathrm{T}$ cell function. Am J Physiol Lung Cell Mol Physiol 2008;295:L412-L421. 